\title{
ANAESTHESIA FOR TRACHEAL RESECTION: A NEW WAY TO MANAGE THE AIRWAY
}

\author{
Mounir N. Abou-Madi, Luis Cuadrado, Bruno Domb, Jennifer Barnes, and Davy Trop
}

IN THE LAST SEVERAL YEARS, an increasing number of obstructive, stenotic and traumatic lesions of the trachea have been challenging the restricted capacities of the anaesthetist. ${ }^{1,2}$

Despite improved surgical and anaesthetic techniques, complete control of the airway during tracheal surgery is a continuing cause of major concern. Various approaches have been suggested to deal with the unusual problems of airway control, adequate ventilation, and surgical access to the trachea. High pressure catheter inflation, oxygen-jet ventilation, bronchoscopic injection. two sets of endobronchial tubes with carlens connector, two ventilating systems. left lung ventilation and clamping of right pulmonary artery, and extracorporeal oxygenation have all been attempted and reported in the literature..$^{3-8}$ However, shunting, arterial hypoxaemia, hypercarbia and hypocarbia, atelectasis and interference with surgery have also been among the reported difficulties encountered during the critical stage of tracheal reconstruction. ${ }^{3-8}$

In search of a better airway control we have, therefore, studied the design characteristics and tested the possibility of modifying a Foley catheter to serve as a tracheal tube. Specifically the Foley catheter is soft, supple, flexible, and nonkinking. When inflated, its $5 \mathrm{ml}$ capacity flat rounded balloon measures less than $1.5 \mathrm{~cm}$ in length and the catheter tip can easily be cut off immediately beyond the cuff. To our knowledge, no conventional tracheal tube with its long cylindrical cuff design, will allow bilateral lung ventilation through such a short tracheal stump. Dealing with lesions of the lower trachea, these added millimetres can play a decisive role in the choice of ventilation.

\section{The airway}

A number 28 Foley catheter, with a balloon

The Department of Anaesthesia, Montreal Neurological Institute, Montreal Chest Hospital Centre, and McGill University.

Presented at the Meeting of the Association of Anaesthetists of Quebec, May 4-5, 1978.

Please address communications to: M.N. AbouMadi, M.D., Department of Anaesthesia. Montreal Neurological Hospital, 3801 University Street, Montreal, Quebec. Canada, H3A 2B4.

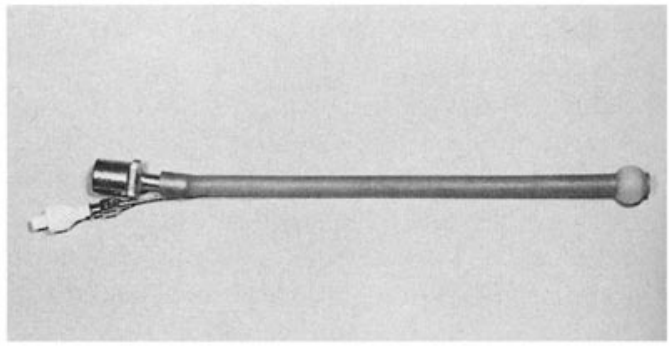

FIgURE 1 The airway: a Foley catheter modified by cutting off both ends.

capacity of $5 \mathrm{ml}$ and an internal diameter of approximately $6 \mathrm{~mm}$, was cut down to a length of $25 \mathrm{~cm}$. To inflate the balloon, a blunt needle with a one-way valve was inserted into the side tube at the cut end of the catheter. A standard $15 \mathrm{~mm}$ metal connector was used to fit a Bain circuit. Finally the catheter tip was cut off exactly beyond the lower border of the balloon (Figure 1).

\section{The patient}

The patient was a 26-year-old otherwise healthy female, scheduled for the resection of a muco-epidermoid tumour of the lower trachea. The AP tomogram revealed the presence of a lateral intratracheal, rounded, soft tissue density, $2 \mathrm{~cm}$ in diameter and approximately $4 \mathrm{~cm}$ from the carina (Figure 2). All other laboratory studies were normal.

\section{Anaesthetic technique}

The patient was premedicated with meperidine and atropine and, after induction with thiopentone and succinylcholine, the trachea was intubated and the lungs were ventilated mechanically. Anaesthesia was maintained with nitrous oxide, oxygen, fentanyl, and d-tubocurarine. The trachea was exposed through a classical midline sternotomy incision. Following division of the trachea, ventilation was restored with a size 6 Portex tracheal tube placed into the distal stump. It was soon discovered that the tube had to be pushed endobronchially to allow surgical access to the trachea. The Portex tube was removed and the modified Foley catheter was passed through to just above the carina. As expected, the cuff seal was satisfactory, tube stability was good and 
TABLE I

Arterial Blood Gases During Anaesthesia. Position of Ventilating Tube Tip

\begin{tabular}{lccccc}
\hline & $\begin{array}{c}\text { Trachea } \\
\text { above tumour }\end{array}$ & $\begin{array}{c}\text { Endobronchial } \\
\text { right }\end{array}$ & $\begin{array}{c}\text { Foley } \\
\text { above carina }\end{array}$ & $\begin{array}{c}\text { Trachea } \\
\text { after reconstruction }\end{array}$ & $\begin{array}{c}\text { Recovery Room } \\
\text { extubated }\end{array}$ \\
\hline $\mathrm{FI}_{\mathrm{O}_{2}}$ & 0.4 & 0.5 & 0.5 & 0.5 & 0.35 \\
$\mathrm{PO}_{2} \mathrm{kPa}$ (torr) & $21.28(160)$ & $8.25(62)$ & $17.96(135)$ & $17.29(130)$ & $13.57(102)$ \\
$\mathrm{PCO}_{2} \mathrm{kPa}$ (torr) & $4.79(36)$ & $5.05(38)$ & $4.66(35)$ & $4.26(32)$ & $4.66(35)$ \\
$\mathrm{H}^{+} \mathrm{nmol} \cdot \mathrm{L}(\mathrm{pH})$ & $42.66(7.37)$ & $45.71(7.34)$ & $45.71(7.34)$ & $42.66(7.37)$ & $45.71(7.34)$ \\
$\mathrm{HCO}_{3}-\mathrm{mmol} \cdot \mathrm{L}$ & 20 & 20 & 18 & 18 & 18 \\
\hline
\end{tabular}

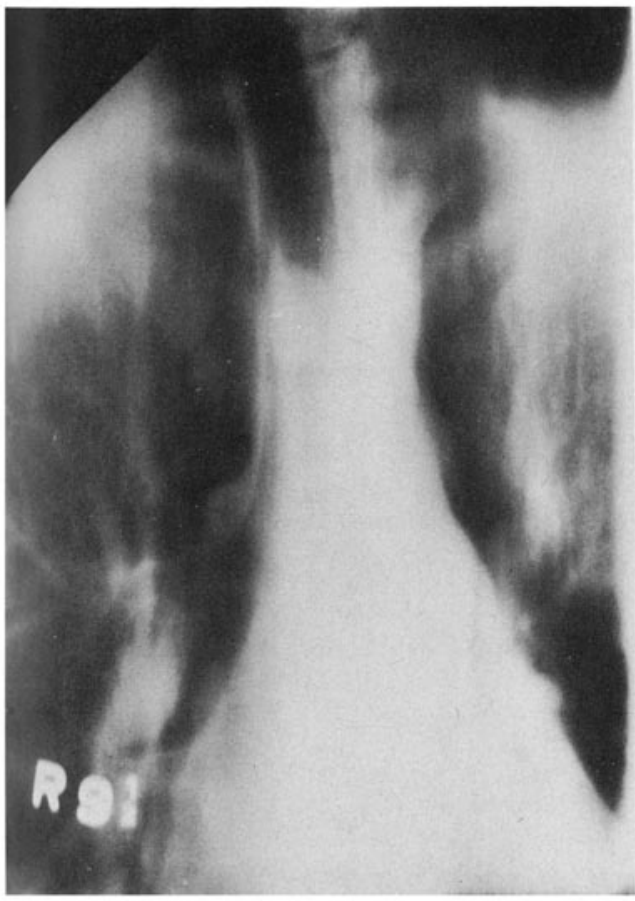

FIgure 2 AP tomogram of tracheal lesion showing the round soft tissue density projected over the upper tracheal air column, $2 \mathrm{~cm}$ in diameter and approximately $4 \mathrm{~cm}$ from the carina.

ventilation was smooth and bilateral (Figure 3). The lungs were ventilated manually to allow for breath to breath control of the air flow. Surgery was not hurried or hampered by the presence of the tube; a circumferential resection of $3 \mathrm{~cm}$ of tracheal length was required to clear the incision lines from tumour. The upper tracheal segment was mobilized and the posterior layer of the anastomosis started. Here, too, the Foley catheter provided excellent surgical exposure. As the anterior wall anastomosis neared completion, the Foley catheter was withdrawn and ventilation was restored from above. At the end of the procedure the patient was extubated and allowed to breathe spontaneously. Her head was kept in flexion to minimize tension on the suture line.

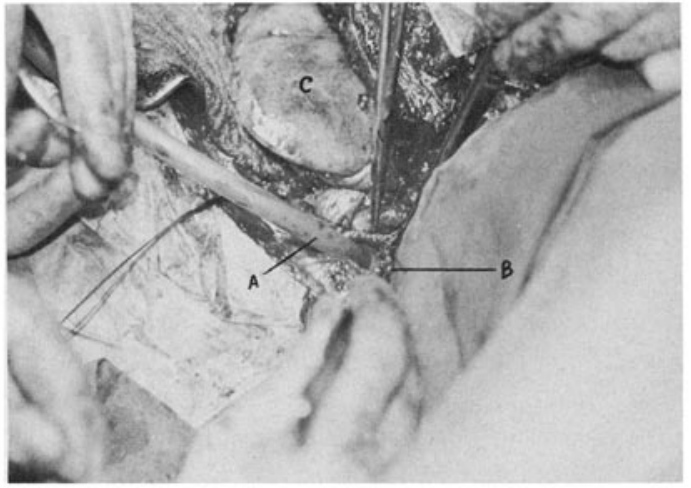

FIgURE 3 Modified Foley catheter in distal tracheal stump; note: A. Foley catheter in distal trachea, with balloon inflated, directed caudad to expose posterior tracheal margin. B. Posterior edge of distal trachea. C. Right lung, upper lobe.

Postoperative chest X-ray revealed no signs of aspiration or atelectasis. Arterial blood gases during the different stages of the procedure are shown in Table I.

\section{Discussion}

Various reports in the past have described a multitude of approaches to the unending problem of airway management during anaesthesia for tracheal resection and reconstruction. They amply emphasized expertise, alertness, precision, planning and team effort to overcome these difficulties. Unfortunately, however, none of the techniques reported could be considered ideal or classified as absolutely safe. Essentially, problems with the ventilation might arise, either during the initial phase of the operation or following the transection of the trachea.

Initially, therefore, induction of general anaesthesia could result in acute complete obstruction of the airway, a traumatic intubation could lead to bleeding and oedema and a polypoid tumour could act as a ball valve blocking and impeding passive expiration. 
These complications should be offset by a careful preoperative assessment of the airway and the subsequent choice of a suitable induction and intubation technique. In managing the second phase, following division of the trachea, Macnaughton, ${ }^{3}$ Baraka, ${ }^{4}$ and Lee and English ${ }^{5}$ showed that adequate ventilation could be maintained with jet ventilation. Technically, however, the airway was left unprotected, ${ }^{3.5}$ and in Baraka's series, ${ }^{4}$ ventilation of one lung by oxygen jet resulted in marked hypoventilation and arterial hypoxaemia. Butlin, et al. ${ }^{6}$ and Dodge, et $a l^{7}$ intubated both lungs separately using two smallbore tracheal tubes. Two separate gas machines were used in Dodge's reported case. Apart from obscuring the operative field, accommodating two tracheal tubes in the distal trachea would also distort the lower tracheal segment and render the posterior layer anastomosis extremely difficult.

Geffin, et al, ${ }^{8}$ in dealing with lesions of the lower trachea, suggested advancing the tracheal tube down the left main bronchus and clamping of the right pulmonary artery.

Finally, some tracheal tumours have been resected using extracorporeal circulation; however, handling the lungs during surgery has led to major intrapulmonary bleeding problems. ${ }^{8}$

In the present report, we have been able to prove that bilateral lung ventilation, airway protection and excellent surgical accessibility can all be achieved with the use of the modified Foley catheter for distal tracheal ventilation. A large bore Foley catheter (28-30) will minimize expiratory resistance and, therefore, allow normal respiratory airfiow.

The flat, short catheter balloon is certainly unique in allowing bilateral lung ventilation for very low end-to-end anastomosis of the trachea.

In conclusion, ventilation through a modified Foley catheter proved to be technically feasible. It achieved ventilation through a very short stump of trachea, afforded complete protection against aspiration, secured bilateral ventilation, spared the use of cumbersome equipment and facilitated unrestricted surgical access to the trachea.

\section{SUMMARY}

A case of lower tracheal resection is reported. A number 28 Foley catheter was modified and successfully used to ventilate the lungs through the short distal tracheal stump.

\section{RÉSUMÉ}

L'utilisation d'une sonde vésicale de Foley, de calibre 28 (diamètre $9.33 \mathrm{~mm}$ ) pour assurer la ventilation pulmonaire lors d'une résection de la trachée, est rapportée. La sonde possède un ballonnet étroit, très proche de l'extrèmité distale, après résection du bout de la sonde. Ces charactéristiques permettent l'intubation d'un moignon de trachée de moins de $3 \mathrm{~cm}$ au dessus de la carène, et une ventilation bilatérale durant la fermeture de la trachée.

\section{REFERENCES}

1. Coulson, A.S., Rossiter, S.J., \& Guernsey, J.M. Progressive tracheal obstruction. J. Thorac. Cardiovasc. Surg. 67: 733-743 (1974).

2. Lefemine, A., Macdonnell, K., \& Moon, H. Tracheal stenosis following cuffed tube tracheostomy, Ann. Thorac. Surg. 15: 456-462 (1973).

3. MaCnaughton, F.I. Catheter inflation ventilation in tracheal stenosis. Brit. J. Anaesth. 47: $1225-1227$ (1975).

4. BaraKa, A. Oxygen-jet ventilation during tracheal reconstruction in patients with tracheal stenosis. Anesth. Analg. 56: 429-432 (1977).

5. LeE, P. \& English, I.C.W. Management of anaesthesia during tracheal resection. Anaesthesia 29: 305-306 (1974)

6. Butlin, G.R., Sellery, G.R.. \& Spoerel, W.E. An unusual airway problem. Canad. Anesth. Soc. J. 17: 78-82 (1970).

7. Dodge, T.L.. Mahaffey, J.E., \& Thomas, J.D. The anesthetic management of a patient with an obstructing intratracheal mass: a case report. Anesth. Analg. 56: 295-298 (1977).

8. Geffin, B., Bland, J., \& Grillo, H.C. Anesthetic management of tracheal resection and reconstruction. Anesth. Analg. 48: 884-894 (1969). 